\title{
RESSIGNIFICAÇÃO DAS CONCEPÇÕES DE NATUREZA, MEIO AMBIENTE E EDUCAÇÃO AMBIENTAL ATRAVÉS DE ỦMA TRILHA ECOLÓGICA
}

\author{
Lana Beatriz Corrêa Pinheiro ${ }^{1}$ \\ Francielber de Souza Lima² \\ Tainá Teixeira Rocha ${ }^{3}$ \\ Ana Cláudia Caldeira Tavares-Martins ${ }^{4}$
}

Resumo: $O$ pensamento ético em volta do futuro do planeta implica responsabilidade à Educação Ambiental cultivada em espaços de produção do conhecimento. Assim, torna-se indispensável, no que diz respeito às discussões sobre o meio ambiente, pesquisar as percepções dos atores escolares e dos grupos sociais submersos na interação de ensino e aprendizagem dessa temática. Este estudo visou analisar as concepções sobre Natureza, Meio Ambiente e Educação Ambiental trazida pelos alunos de $6^{\circ}$ e $7^{\circ}$ anos do ensino fundamental II, e posteriormente ressignificá-las através de uma trilha ecológica.

Palavras-chave: Conhecimento; Ensino; Aprendizagem. 


\section{Introdução}

Até a Conferência de Estocolmo, o ambiente era aceito pela formação fauna/flora e os aspectos abióticos. A partir de então, ele passou a ser determinado pelo arranjo: fauna/flora + abióticos + cultura humana, colocando a Educação Ambiental numa abordagem holística, ou seja, considerando todos os aspectos da vida (DIAS, 2006).

Neste sentido, nos diversos desafios que se oferecem à Educação Ambiental nos dias de hoje, inclui-se a batalha de superar os aspectos meramente biológicos e agrupar os ares antropológicos (REIGOTA, 2010). A Educação Ambiental contribui com a redefinição do homem enquanto ser da natureza, sem a perda de identidade ou pertencimento deste a uma dada espécie com todos os seus atributos (LOUREIRO, 2006).

Por haver uma dificuldade na significação de Educação Ambiental, a formação humana e a experiência profissional dos que com ela atuam acabam por construir o seu conceito (SANTOS, 2007). Os entendimentos que expomos das situações, dependem dos significados que estabelecemos ao longo da vida, em decorrência de nossas experiências, onde cada conceito expressa uma forma de interpretação (MORAES, 2009).

O pensamento ético em volta do futuro do planeta implica responsabilidade com a Educação Ambiental cultivada em espaços de produção do conhecimento (ALMEIDA; ORTIZ, 2006). Assim, torna-se indispensável, no que diz respeito às discussões sobre o meio ambiente, pesquisar as percepções dos atores escolares e dos grupos sociais submersos na interação de ensino e aprendizagem dessa temática (SILVA, 2009).

Este estudo visou analisar as concepções sobre Natureza, Meio Ambiente e Educação Ambiental trazida pelos alunos, e posteriormente ressignificá-las através de uma trilha ecológica.

\section{Material e métodos}

A pesquisa foi realizada com alunos do Ensino Fundamental II da Escola em Regime de Convênio Estadual de Ensino Fundamental e Médio Cristo Redentor. Instituição educacional pertencente à Diocese de Abaetetuba-Pa, conveniada com a Secretaria Executiva de Educação do Estado do Pará (SEDUC-PA), no município de Abaetetuba (PA), bairro Cristo Redentor.

A trilha utilizada é um fragmento de floresta secundária pertencente ao Centro Bíblico de Abaetetuba-PA, situado no bairro Aviação. A extensão da trilha foi de aproximadamente 250 metros de comprimento com trechos variando entre 01 e 02 metros de largura. $O$ percurso da trilha foi estruturado em três estações, onde foram apresentadas: quatro concepções de natureza, meio ambiente e Educação Ambiental.

A pesquisa caracterizou-se como ativa do tipo participativa, a qual denota a inclusão dos envolvidos na pesquisa, e pressupõe a democratização 
da produção do conhecimento e da sociedade, a fim de orientar a prática (CHIZZOTTI, 2011).

A análise e ressignificação das diferentes concepções sobre natureza, meio ambiente e Educação Ambiental foi feita de forma sistemática. Arruda (2008) entende ressignificação como o processo de repensar um valor e modificá-lo atribuindo outro sentido ou significado.

Crentes do dinamismo inerente à temática ambiental, este trabalho não pretendeu apontar o que é certo ou errado em relação às concepções, mas sim expandi-las a fim de que se possa ter maior compreensão sobre a complexidade da Educação Ambiental.

A coleta de dados aconteceu entre os meses de dezembro de 2012 e setembro de 2013. Foi realizada uma análise do Projeto Político Pedagógico (PPP) onde se procurou identificar ações escolares voltadas à Educação Ambiental com base em Ferrari e Zancul (2010).

Para conhecer as concepções de natureza, meio ambiente e Educação Ambiental de cada aluno, utilizou-se a técnica de mapa mental que consiste em maneira mais fácil de introduzir e de extrair informações do cérebro, mapeando os pensamentos de forma criativa e eficaz (BUZAN, 2011).

Assim sendo, baseados em Aires e Bastos (2011) com adaptações, foi solicitado aos estudantes que individualmente representasse por meio de mapa mental o que entendiam por: natureza; meio ambiente e Educação Ambiental. E que levassem em consideração os conhecimentos do seu dia a dia, o lugar onde moram e as ideias e concepções tratadas no âmbito escolar pelos professores em relação a esses assuntos.

Esse método foi aplicado em dois momentos, antes e após a intervenção realizada na trilha: antes se objetivou conhecer as concepções que os alunos traziam consigo e depois para verificar sob a ótica da ressignificação se houve a expansão das concepções.

Após a intervenção, optou-se por classificar em agrupamentos as agregações de concepções apresentadas em cada categoria e foram representados pela letra $(A)$ seguida de uma numeração sequencial. Assim, as representações da categoria natureza compreendem de (A1) a (A5), meio ambiente (A6) a (A13) e Educação Ambiental (A14) e (A15).

Para a análise da categoria Natureza utilizou-se as concepções definidas por Tamaio (2002), à saber: romântica, utilitarista, científica, generalizante, naturalista e socioambiental.

Para a categoria Meio Ambiente fundamentou-se na proposta de Sauvé (2005), onde a natureza é vista como: natureza, recurso, problema, sistema, lugar em que se vive, contexto, território, paisagem, biosfera e projeto comunitário.

Para a categoria Educação Ambiental baseou-se na proposta de Sauvé (2005), onde são apresentadas 15 correntes sendo algumas antigas e outras 
mais recentes. Entre as mais antigas estão: naturalista, conservacionista/recursista, resolutiva, sistêmica, científica, humanista e moral/ética. Entre as correntes mais recentes estão: holística, biorregionalista, práxica, crítica social, feminista, etnográfica, eco-educação e sustentabilidade.

Análise dos dados foi feita através da caracterização do perfil de alunos, além da influência da trilha ecológica no incremento das concepções sobre Natureza, Meio Ambiente e Educação Ambiental, bem como possíveis ressignificações desses conceitos.

\section{Resultados e discussão}

\section{Perfil dos alunos}

Dos 55 alunos selecionados, 54,5\% correspondem ao 6ㅇ ano e 45,5\% ao $7^{\circ}$ ano. A faixa etária dos participantes amostrados é entre 10 e 16 anos, sendo $45,5 \%$ do sexo feminino e $54,5 \%$ do sexo masculino.

\section{O projeto Político Pedagógico (PPP)}

Dentro do Projeto Político Pedagógico (PPP) da escola estudada, são mencionados projetos permanentes e temporários, sendo que a proposta ambiental só é encontrada no corpo do texto do Programa Mais Educação, um projeto temporário onde uma das atividades sugeridas é a realização de uma oficina sobre meio ambiente. O tema foi abordado na escola exclusivamente sobre a limpeza do ambiente escolar, mostrando uma visão limitada à gestão do lixo.

Segundo Silva et al. (2009) uma maneira de instituir a Educação Ambiental de forma abrangente e continuada na escola é inseri-la por meio de projetos pedagógicos. Ferrari e Zancul (2010) defendem a perspectiva de que a Educação Ambiental, a partir do trabalho pedagógico desenvolvido na escola, deve proporcionar experiências concretas que insiram o educando numa prática social real, para que ele possa construir seus valores e hábitos, colocando-se como ser ativo diante de sua comunidade.

\section{Concepções iniciais dos alunos}

$\mathrm{Na}$ análise individual dos mapas mentais verificou-se a presença de quatro concepções para cada categoria estudada (Tabela 1). 
Tabela 1: Concepção prévia sobre natureza, meio ambiente e Educação Ambiental.

\begin{tabular}{|c|c|c|c|c|c|}
\hline Natureza & $\%$ & Meio Ambiente & $\%$ & Educação Ambiental & $\%$ \\
\hline Romântica & $16,4 \%$ & Natureza & $21,9 \%$ & Naturalista & $15 \%$ \\
\hline Utilitarista & $12,7 \%$ & Problema & $44 \%$ & Conservacionista & $44 \%$ \\
\hline Naturalista & $50.9 \%$ & $\begin{array}{c}\text { Lugar em que se } \\
\text { vive }\end{array}$ & $25,4 \%$ & tiva & $16.4 \%$ \\
\hline Socioambiental & $12,7 \%$ & Biosfera & $1,8 \%$ & Humanista & $14,5 \%$ \\
\hline Não elucidado & $7 \%$ & Não elucidado & $7 \%$ & Não elucidado & $10,9 \%$ \\
\hline
\end{tabular}

Fonte: Autoria própria.

Para a categoria natureza $16,4 \%$ dos mapas mentais ilustraram a concepção romântica (Figura 1). Essa concepção revela uma natureza sempre harmônica, com equilíbrio e beleza estética (TAMAIO, 2002).

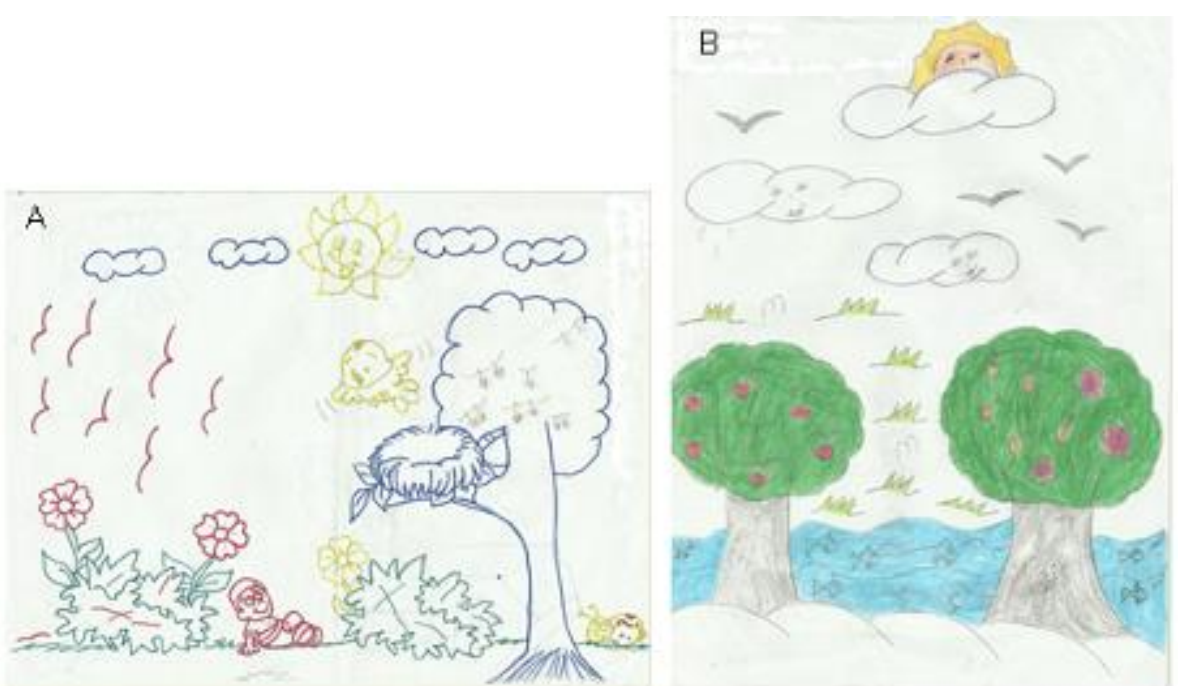

Figura 1: $\mathrm{A}$ e $\mathrm{B}$ - Exemplos de representações da natureza na concepção romântica.

Fonte: A - Z.F., $7^{\circ}$ ano (2013); B - G.A. $-6^{\circ}$ ano (2013).

Nestes mapas mentais percebeu-se que elementos como sol, nuvens, animais foram personificados. A forma original ganhou um contorno diferenciado mais humanizado, em alguns mapas apresentou-se figuras de animais mitológicos.

Essa visão verificada também expressou a grandiosidade da natureza como um ambiente harmônico, sem a presença do homem e suas atribuições que, de acordo com Reigota (2010), na dicotomia homem x natureza, ele se considera um observador e/ou explorador dela.

Uma parte dos alunos (12,7\%) entende natureza como fornecedora de vida e recursos ao ser humano, que de acordo com a classificação de Tamaio (2002) revela uma natureza utilitarista (Figura 2). 

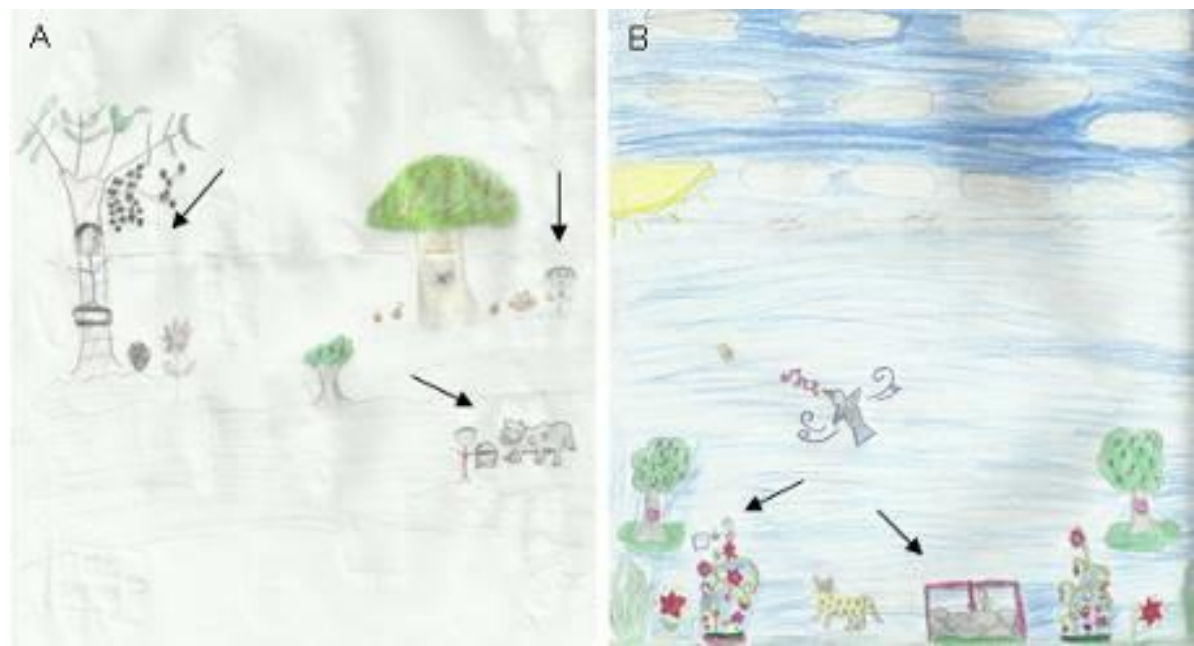

Figura 2: A e B - Exemplos de representações da natureza na concepção utilitarista.

Fonte: A - J.G., $6^{\circ}$ ano (2013); B - C.A. $-6^{\circ}$ ano (2013).

Observou-se com maior frequência nesses mapas mentais a presença de árvores, sol, nuvens, arco-íris, animais e a presença do homem apropriando-se dos recursos oferecidos pela natureza. Dessa forma, ela apresenta-se como objeto de indispensável valor para fins superiores. Esse modo de ver a natureza refere-se a uma leitura antropocêntrica, onde evidencia a utilidade dos recursos naturais para a sobrevivência do ser humano. Almeida e Ortiz (2006) elucidam que com o objetivo de atender às suas necessidades, 0 homem domina a natureza, provocando sérios impactos ambientais.

Grande porcentagem dos estudantes (50,9\%) apresentou a concepção naturalista de natureza (Figura 3) que segundo Tamaio (2002) se refere a tudo que não sofreu ação de transformação pelo homem: as matas, bichos, entre outros.

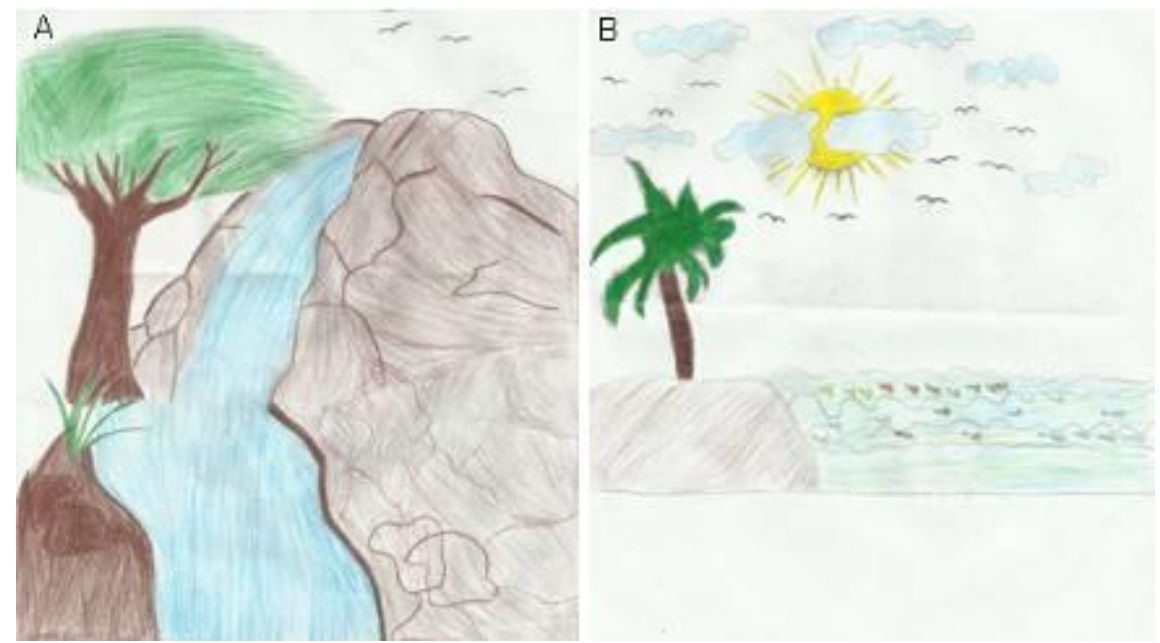

Figura 3: $\mathrm{A}$ e $\mathrm{B}$ - Exemplos de representações da natureza na concepção naturalista.

Fonte: A - E.A., $6^{\circ}$ ano (2013); B - T.S. $-7^{\circ}$ ano (2013). 
Nos mapas mentais observou-se o elemento floresta com sua fauna e flora exuberante. Todos caracterizam ambientes naturais como montanhas, florestas, cachoeiras, animais, lagos, sol, nuvem, rio. As formas originais foram fielmente reproduzidas. Essa leitura da natureza como um espaço constituído apenas por elementos vivos (animais, plantas) e não vivos (sol, lago, nuvens, igarapés) excluindo o ser humano e todas as suas produções, denota reducionismo. Além disso, a compreensão de natureza acaba reduzindo-se aos conhecimentos sobre ecossistema. A característica marcante nesses desenhos é a natureza sem a presença do homem ou não modificada por ele.

Segundo Carvalho (2006) a visão naturalista fundamenta-se, sobretudo na percepção da natureza como fenômeno estritamente biológico, autônomo, alimentando a ideia de que há um mundo natural constituído em oposição ao mundo humano.

A concepção socioambiental de natureza foi apresentada por $12,7 \%$ dos estudantes (Figura 4). Ela desenvolve uma abordagem histórico-cultural, reintegrando o homem à natureza e às vezes, ele surge como responsável pela degradação ambiental (TAMAIO, 2002).

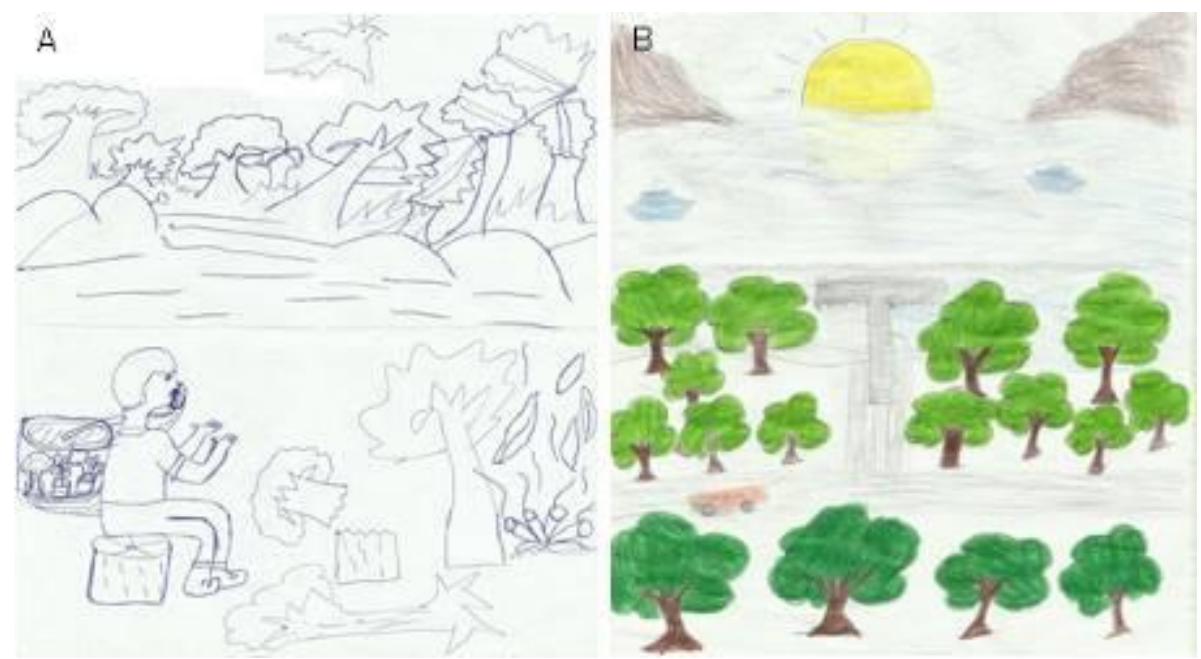

Figura 4: A e B - Exemplos de representações da natureza na concepção socioambiental. Fonte: A - F.C., $7^{\circ}$ ano (2013); B - V.B. $-6^{\circ}$ ano (2013).

Entre os desenhos apresentou-se os indicativos naturais como montanhas, árvores, animais, sol, nuvens, rios e peixes, e os socioculturais representados por casas, praças, pontes, meio de transporte aquáticos e terrestres, etc. Essa leitura inclui os aspectos naturais e os resultantes das atividades humanas, sendo assim o resultado da interação de fatores biológicos, físicos, econômicos e culturais. Nesta representação emergiu a figura humana, o que denota uma amplitude na visão desta categoria. Estes alunos compreendem a dimensão humana e o ambiente construído como elementos constitutivos desta. Para Dulley (2004, p.17) "o homem nasce num ambiente natural, mas simultaneamente num ambiente sociocultural". 
O meio ambiente como natureza foi concebido por $21,9 \%$ dos estudantes (Figura 5). De acordo com Sauvé (2005) esta concepção considera como componentes em interação no meio ambiente somente os aspectos físicos naturais bióticos e abióticos.
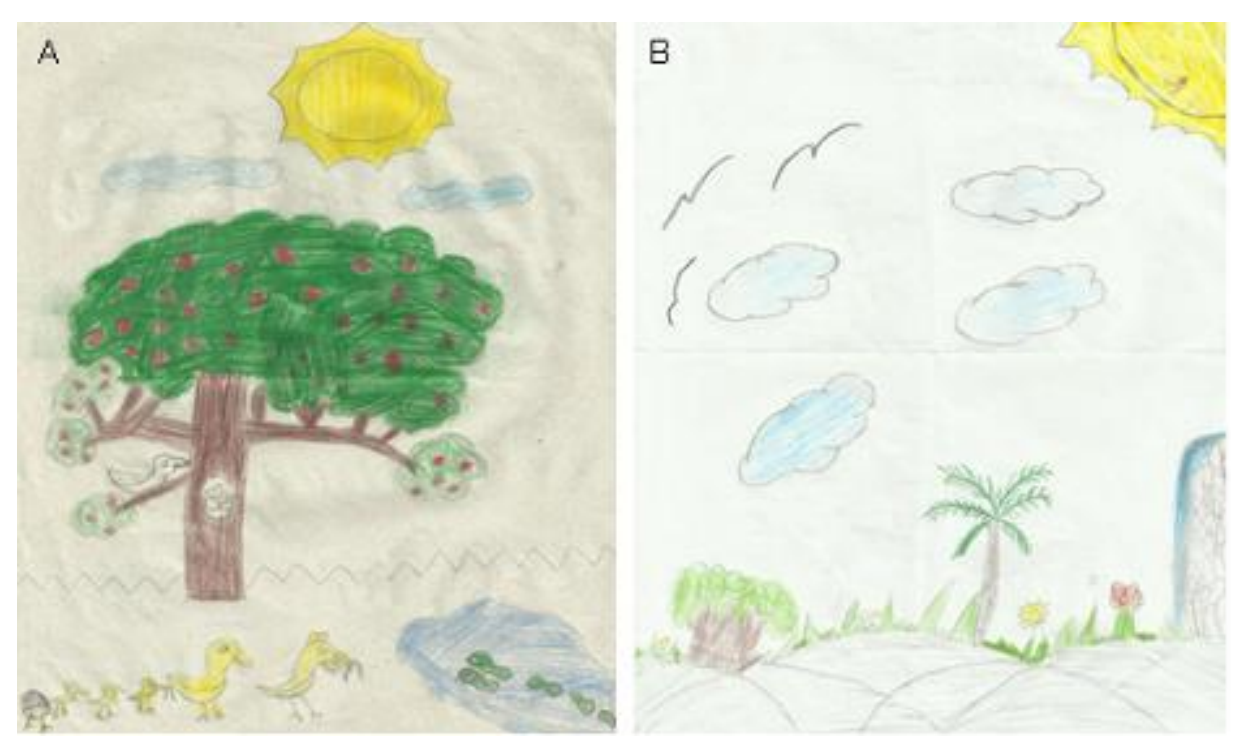

Figura 5: A e B - Exemplos de representações de meio ambiente na concepção de natureza. Fonte: A - L.D., $6^{\circ}$ ano (2013); B - L.M. $-7^{\circ}$ ano (2013).

Entre os elementos mais frequentes nestas gravuras citaram-se as florestas com árvores, animais, sol, montanhas, cachoeira. Em nenhum momento a presença humana e suas intervenções foram enfatizadas. Para Carvalho (2006) esse conceito o reduz a suas condições físicos-biológicas de funcionamento.

A constatação de meio ambiente como um espaço restrito à fauna e a flora expõe a inexistência de qualquer relação entre o homem e o meio, na qual o ser humano despreza suas modificações sobre ele ao longo do tempo. Essa é uma percepção ingênua e reducionista, que segundo Reigota (2010) carrega consigo uma visão naturalizada de meio ambiente, relacionando-o somente a elementos naturais e puros. Desse modo, Dias (2006) ressalta que o meio ambiente deve ser percebido em sua totalidade, ou seja, considerando a interação dos aspectos naturais e os criados pelo homem.

Quase a metade dos alunos (44\%) entende meio ambiente como problema (Figura 6), o que de acordo com Sauvé (2005) exige o desenvolvimento de habilidades de investigação crítica para prevenir, para resolver problemas reais. 

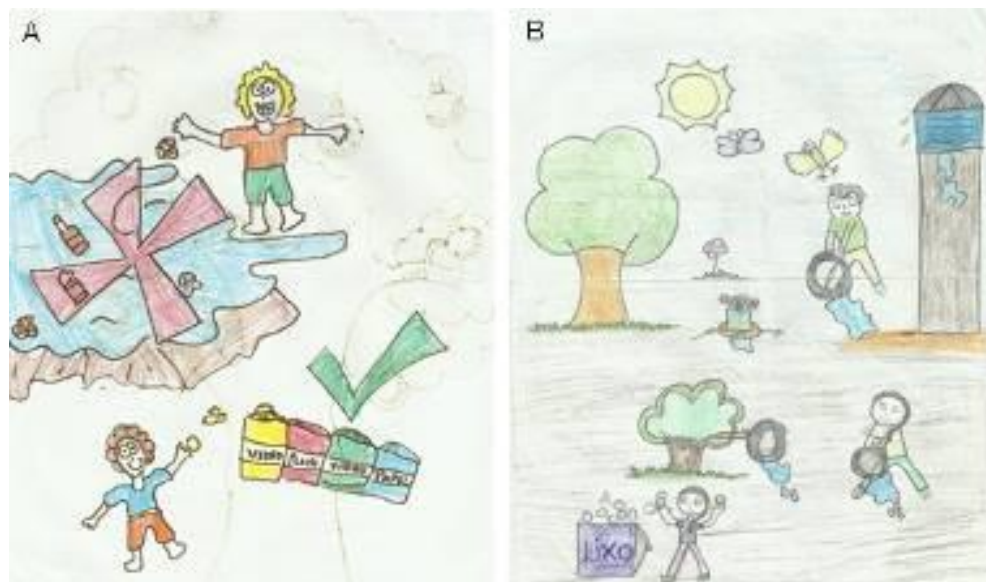

Figura 6: $\mathrm{A}$ e $\mathrm{B}$ - Exemplos de representações de meio ambiente na concepção de problema.

Fonte: A - M.B., $6^{\circ}$ ano (2013); B - E.A. $-6^{\circ}$ ano (2013).

A maior parte dos mapas mentais apresentou, além dos elementos naturais, os que remetem as ações voltadas para o cuidado com o meio ambiente tais como lixeiras, coleta seletiva e placas de conscientização. A presença do homem poluindo ou conservando o meio também é enfatizada nos apontando a uma necessária reflexão sobre os desafios para mudar as formas de pensar e agir em torno da questão ambiental (JACOBI, 2003).

O desenvolvimento de ações que visam à resolução imediata de problemas ou a modificação de comportamentos nas pessoas é resultado da percepção humana como parte do meio ambiente. Assim, sensibilizadas com as questões ambientais elas adquirem valores, habilidades e competências para identificar e agir frente ao quadro atual da problemática ambiental.

Meio ambiente como lugar em que se vive foi constatado em $25,4 \%$ dos desenhos (Figura 7). Nessa definição o meio ambiente é visto como meio ou lugar de vivência com seus componentes sociais, históricos e tecnológicos, é o ambiente da vida cotidiana, na escola, em casa, no trabalho (SAUVÉ, 2005).
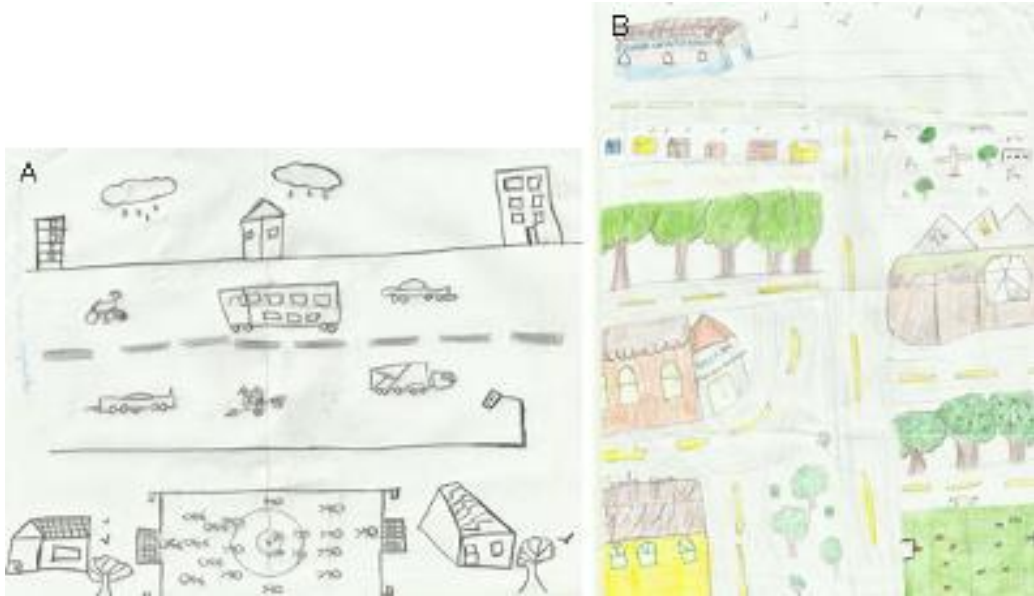
A influência mútua entre os elementos naturais (árvores, animais, lagos, nuvens) e o ambiente construído (prédios, casas, escolas, hospitais, praças, igrejas, ruas, meios de transporte) destacou-se nas gravuras. Nessa representação emergiu a figura humana e suas interrelações com o espaço natural e o edificado. De acordo com Carvalho (2002, p. 39) "o homem não só depende do meio ambiente, mas dele faz parte".

A junção dos aspectos naturais às transformações humanas reflete o entendimento de uma exploração individual do meio ambiente. Esse enfoque mais ampliado permite a contemplação das interdependências que permeiam o lugar em que se vive, ou seja, proporciona uma decodificação fiel da realidade.

A concepção biosfera foi percebida em $1,8 \%$ das gravuras (Figura 8 ), a qual apreende meio ambiente como local de interdependência dos seres vivos com os demais componentes da Terra (SAUVÉ, 2005).

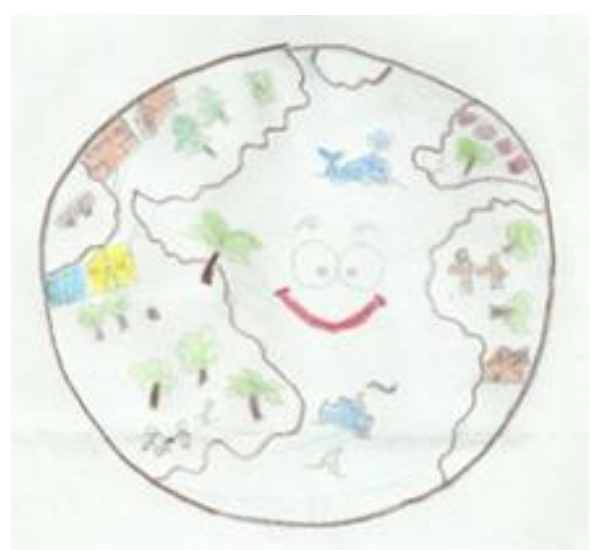

Figura 8: Exemplo de representação de meio ambiente na concepção biosfera. Fonte: A - R.S., $7^{\circ}$ ano (2013).

No mapa mental observou-se a representação do planeta Terra, com suas florestas, praias, oceanos, navios, habitações, seres humanos e as possíveis interações existentes entre estes componentes. Em Sauvé (2005) essa interpretação do meio ambiente explicita o emaranhado de relações que permeiam entre este e a sociedade global.

A visão que comporta as organizações políticas, culturais, econômicas, éticas, religiosas, artísticas ou ecológicas em sua amplitude, abriga uma compreensão abrangente das relações que podem ocorrer tanto a nível local como a nível planetário (DIAS, 2006). Além disso, proporciona reflexão a respeito do desenvolvimento das corporações humanas, sobretudo, a maneira como encarar os desafios ambientais, e admite-se que as comunidades não podem viver isoladas.

Para Educação Ambiental em $15 \%$ dos desenhos foi identificada a corrente naturalista (Figura 9). Essa corrente está centrada na relação com a 
natureza. $O$ enfoque educativo pode ser cognitivo, experiencial, afetivo, espiritual ou artístico (SAUVÉ, 2005).

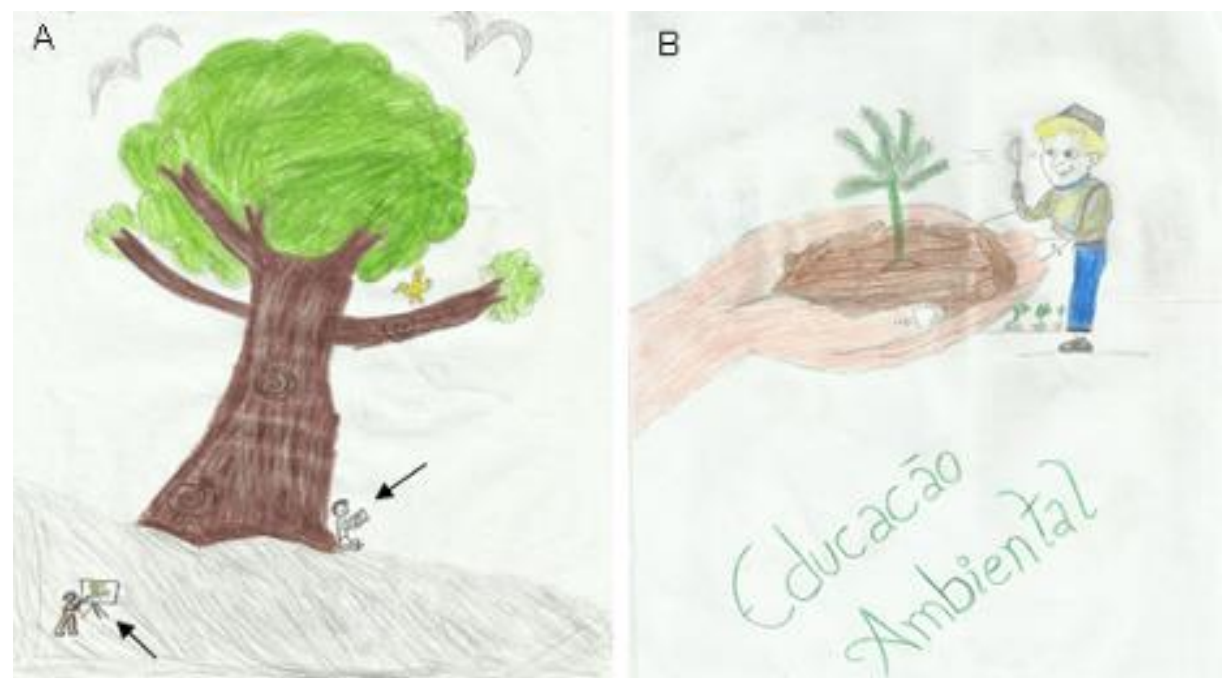

Figura 9: $\mathrm{A}$ e $\mathrm{B}$ - Exemplos de representações de meio ambiente na concepção naturalista. Fonte: $\mathrm{A}-$ L.A., $6^{\circ}$ ano (2013); B - R.C. $-7^{\circ}$ ano (2013).

Nestes mapas mentais a maior parte exibiu os elementos da fauna e da flora e o surgimento do homem. Entendeu-se que a presença humana na natureza expôs a relação de aprendizagem e criatividade influenciadas pela mesma. É enfatizada a ideia de que para intervir nos problemas ambientais é necessário entender o funcionamento da natureza (SAUVÉ, 2005).

É importante ter conhecimento sobre o mundo biológico, sobretudo quando as discussões envolvem certos fenômenos naturais. Porém, ao expandir o conhecimento sobre a natureza abarcando a origem das problemáticas ambientais será possível pensar em uma Educação Ambiental emancipatória.

Enfatizar a incorporação dos vários aspectos que permeiam a relação homem/meio ambiente figura entre os vários compromissos que competem à Educação Ambiental. De acordo com Carvalho (2006, p. 125) "não se trata, de negar o valor do conhecimento científico da natureza e de suas aplicações tecnológicas, mas de torná-los objeto de compreensão crítica".

$\mathrm{Na}$ corrente conservacionista/recursista (Figura 10) foram incluídos $44 \%$ dos desenhos. De acordo com Sauvé (2005, p. 19), "esta corrente agrupa as proposições centradas na 'conservação' dos recursos, tanto no que concerne à sua qualidade quanto à sua quantidade". 


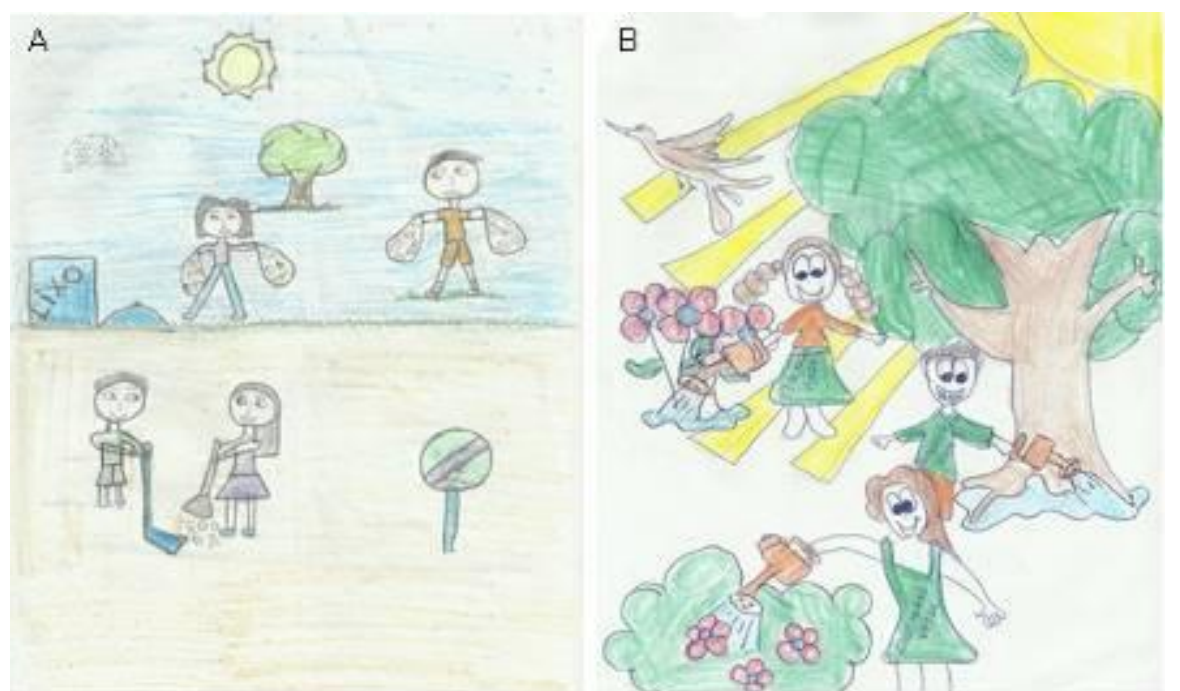

Figura 10: A e B - Exemplos de representações de meio ambiente na concepção conservacionista/recursista.

Fonte: A - R.L., $6^{\circ}$ ano (2013); B - A.L. $-6^{\circ}$ ano (2013).

Nessas gravuras destacaram-se além dos elementos bióticos e abióticos, as placas sobre o lixo, pessoas plantando, cuidando dos animais, limpando o ambiente e realizando campanha para prevenção de doenças. Percebeu-se aqui a motivação de uma ação de conscientização para conservação tanto dos recursos naturais quanto dos construídos pelo homem. Estas informações indicam um forte apelo para a gestão dos recursos ambientais como verificado em Sauvé (2005).

Basear-se num conhecimento fechado, a partir de um ponto de vista simplista da realidade ambiental não permite ao homem a contemplação da complexidade que envolve a temática ambiental. Reigota (2010) afirma que "o desafio da Educação Ambiental é sair da ingenuidade e do conservadorismo (biológico e político) a que se viu confinada e propor alternativas sociais, considerando a complexidade das relações humanas e ambientais".

A corrente resolutiva (Figura 11) ficou explícita em 16,4\% dos desenhos. Nesta visão o meio ambiente é visto, sobretudo, como um conjunto de problemas. Desse modo a Educação Ambiental deve atuar no sentido de informar ou de levar as pessoas a se informarem sobre problemáticas ambientais, através da identificação e pesquisa de uma situação, diagnóstico, busca, avaliação e escolha de soluções (SAUVÉ, 2005). 


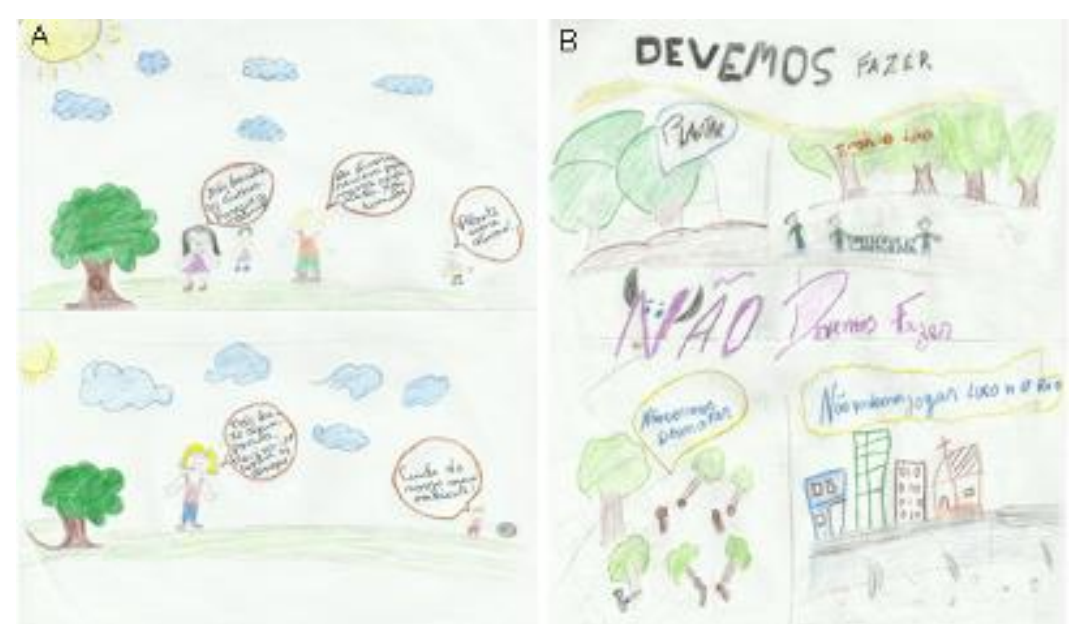

Figura 11: A e B - Exemplos de representações de meio ambiente na concepção resolutiva. Fonte: A - M.S., $6^{\circ}$ ano (2013); B - J.S. $-6^{\circ}$ ano (2013).

Como destaque nestes desenhos observou-se o surgimento de balões de texto onde há o diálogo sobre as atitudes ambientalmente corretas, acompanhadas da paisagem natural e a modificada pelo homem. Percebeu-se agora, uma mudança de postura.

A preocupação aqui é identificar e escolher a melhor solução para resolver um problema. Para Dias (2006) a Educação Ambiental deve oferecer às pessoas a possibilidade de adquirir conhecimento, interessse ativo e as atitudes necessárias para proteger e melhorar a qualidade ambiental. A totalidade de práticas em Educação Ambiental precisam estar inseridas no contexto de valores sociais, ainda que remeta à mudanças de atitudes do diaa-dia.

A corrente humanista (Figura 12) foi observada no desenho de $14,5 \%$ dos estudantes. Essa visão para Sauvé (2005) enfatiza a dimensão humana do meio ambiente. O meio ambiente é também o da cidade, da praça pública, dos jardins cultivados.

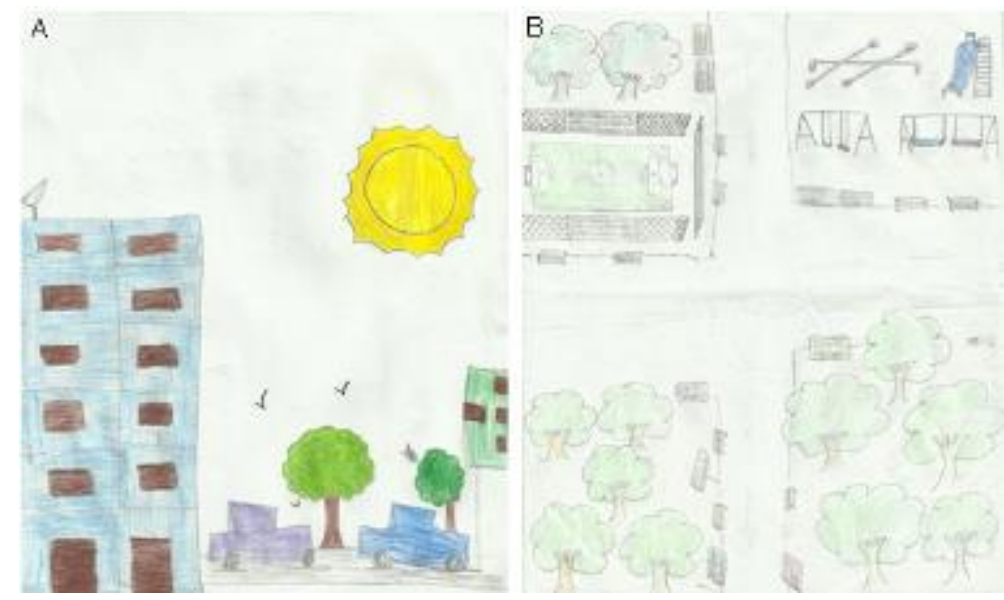

Figura 12: $A$ e $B$ - Exemplos de representações de meio ambiente na concepção humanista. Fonte: A - L.B., $7^{\circ}$ ano (2013); B - N.F. $-6^{\circ}$ ano (2013). 
Nos mapas mentais contemplou-se os aspectos naturais (bióticos e abióticos) e os elementos prédio, casa, veículos, praças e outros espaços públicos. Percebeu-se nas paisagens que a dimensão naturalista está relacionada a um padrão estético e cultural, o patrimônio é tanto natural quanto cultural, caracterizando um ambiente construído e/ou modificado pelo homem, conforme observado em Sauvé (2005).

Aproximar a visão naturalista ao aspecto social e/ou cultural do homem é perceber o meio ambiente na multiplicidade de aspectos. Para Dias (2006) de acordo com os princípios básicos da Educação Ambiental, o meio ambiente deve ser considerado em sua totalidade, isto é, em seus aspectos naturais e criados pelo homem.

\section{Concepção dos alunos após a intervenção na trilha}

Após a intervenção na trilha, os alunos passaram a conceber natureza como o agrupamento das seguintes concepções: (A1) romântica, utilitarista, naturalista, socioambiental; (A2) romântica, utilitarista, socioambiental; (A3) romântica, naturalista, socioambiental; (A4) utilitarista, naturalista, socioambiental e (A5) utilitarista, socioambiental (Tabela 2).

Tabela 2: As concepções de natureza antes e após a trilha (ressignificação).

\begin{tabular}{cccc}
\hline \multicolumn{2}{c}{ Concepção prévia\% } & \multicolumn{2}{c}{ Concepção após a trilha \% } \\
\hline Romântica & $16,4 \%$ & $\mathrm{~A} 1$ & $41,8 \%$ \\
\hline Utilitarista & $12,7 \%$ & $\mathrm{~A} 2$ & $12,7 \%$ \\
\hline Naturalista & $50,9 \%$ & $\mathrm{~A} 3$ & $21,9 \%$ \\
\hline Socioambiental & $12,7 \%$ & $\mathrm{~A} 4$ & $9,1 \%$ \\
\hline Não elucidado & $7 \%$ & $\mathrm{~A} 5$ & $15 \%$ \\
\hline
\end{tabular}

Fonte: Autoria própria.

Com a ressignificação notou-se que os mapas mentais agregaram individualmente mais de uma concepção (Figura 13, página seguinte), e que a maioria dos alunos $(41,8 \%)$, passou a concebê-la de acordo com o agrupamento (A1).

A ressignificação ampliou o entendimento dos alunos sobre natureza, pois eles passaram a compreendê-la com maior extensão, abarcando não só o espaço natural, natureza rústica (LIMA; OLIVEIRA 2011), como também o espaço modificado pelo homem e a interação entre este e os demais seres vivos, abordagem histórico-cultural (TAMAIO, 2002).

Nas concepções prévias, a categoria meio ambiente foi entendida pelos estudantes como natureza, problema, biosfera, lugar em que se vive e um pequeno grupo não elucidaram. 


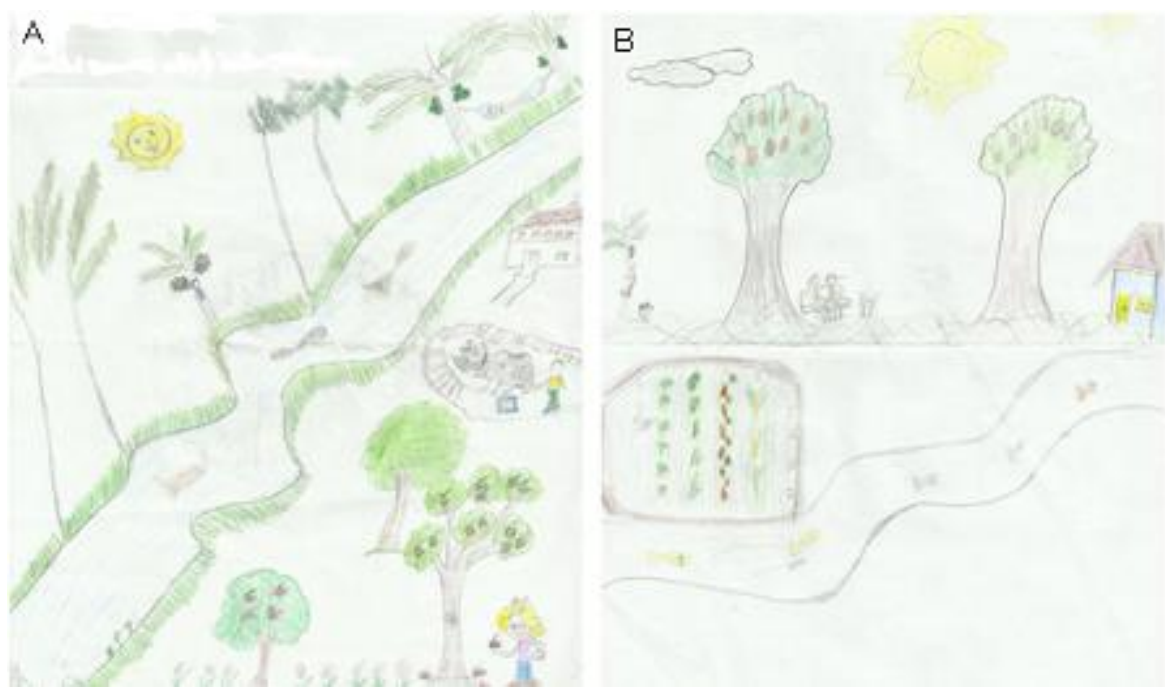

Figura 13: A e B - Exemplos de agrupamentos das concepções de natureza: A) romântica, utilitarista, naturalista, socioambiental; B) utilitarista, naturalista, socioambiental.

Fonte: A - T.S., $7^{\circ}$ ano (2013); B - J.G. $-6^{\circ}$ ano (2013).

Após a ressignificação foram agrupadas as seguintes concepções: (A6) natureza, recurso, lugar em que se vive e problema; (A7) biosfera, natureza, lugar em que se vive e problema; (A8) recurso, problema e lugar em que se vive; (A9) natureza, problema e lugar em que se vive; (A10) natureza, problema e recurso; (A11) lugar em que se vive e problema; (A12) natureza e lugar em que se vive; e (A13) biosfera e lugar em que se vive (Tabela 3 ).

Tabela 3: As concepções de meio ambiente antes e após a trilha (ressignificação).

\begin{tabular}{cccc}
\hline \multicolumn{2}{c}{ Concepção prévia \% } & \multicolumn{2}{c}{ Concepção após a trilha \% } \\
\hline Natureza & $21,9 \%$ & $\mathrm{~A} 6$ & $15 \%$ \\
\hline Problema & $44 \%$ & $\mathrm{~A} 7$ & $13 \%$ \\
\hline $\begin{array}{c}\text { Lugar em que se } \\
\text { vive }\end{array}$ & $25,4 \%$ & $\mathrm{~A} 8$ & $22 \%$ \\
\hline Biosfera & $1,8 \%$ & $\mathrm{~A} 9$ & $11 \%$ \\
\hline Não elucidado & $7 \%$ & $\mathrm{~A} 10$ & $13 \%$ \\
\hline- & - & $\mathrm{A} 11$ & $13 \%$ \\
\hline- & - & $\mathrm{A} 12$ & $9 \%$ \\
\hline- & - & $\mathrm{A} 13$ & $5,5 \%$
\end{tabular}

Fonte: Autoria própria.

Após a ressignificação observou-se nesta categoria a união de distintas concepções em cada desenho e o aparecimento de uma concepção não detectada na análise prévia, mas discutida na intervenção (Figura 14). Houve ainda o predomínio do agrupamento (A8), apresentado por (22\%) dos discentes. 


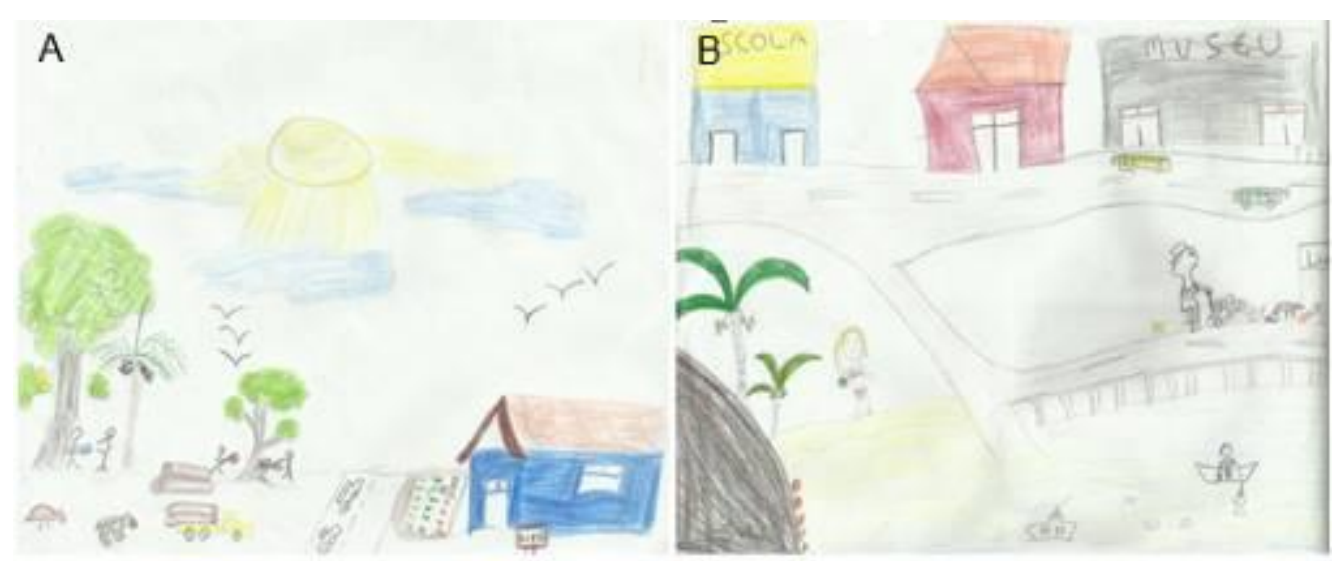

Figura 14: A e B - Exemplos de agrupamentos das concepções de meio ambiente: A) natureza, recurso, lugar em que se vive, problema; $B$ ) recurso, problema, lugar em que se vive.

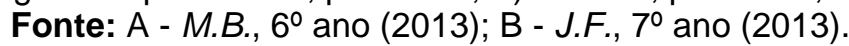

A presença da concepção recurso foi notada nos agrupamentos (A6), (A8) e (A10) que de acordo com Sauvé (2005) essa concepção não pretende tratar da gestão do meio ambiente, mas da gestão de nossas condutas particulares e coletivas com respeito aos recursos essenciais extraídos deste meio.

Entre os elementos dos mapas mentais constaram alguns aspectos que caracterizam essa concepção como: extração de madeira, uma horta, uma pessoa tomando água de coco na praia e um homem pescando. Percebeu-se que o meio ambiente é entendido como uma fonte de matéria-prima à disposição do homem. Ainda nesta categoria observou-se uma maior diversidade de agrupamentos e que o meio ambiente passou a ser percebido como a união dos ares naturais e simultaneamente sociais (BRÜGGER, 2004; TAMAIO, 2002) numa visão ambiental mais ampla que considera a vida em seus vários aspectos, ou seja, como uma abordagem holística (DIAS, 2006).

Para a Educação Ambiental, após a intervenção os alunos incorporaram as seguintes correntes: (A14) conservacionista, resolutiva e humanista e (A15) conservacionista e humanista (Tabela 4).

Tabela 4: As correntes de Educação Ambiental após a ressignificação.

\begin{tabular}{cccc}
\hline \multicolumn{2}{c}{ Concepção prévia \% } & \multicolumn{2}{c}{ Concepção após a trilha \% } \\
\hline Naturalista & $15 \%$ & $\mathrm{~A} 14$ & $70,9 \%$ \\
\hline Conservacionista & $44 \%$ & $\mathrm{~A} 15$ & $29,1 \%$ \\
\hline Resolutiva & $16,4 \%$ & - & - \\
\hline Humanista & $14,5 \%$ & - & - \\
\hline Não elucidado & $10,9 \%$ & - & -
\end{tabular}

Fonte: Autoria própria.

Após a ressignificação percebeu-se que cada mapa mental agregou mais de uma corrente para esta categoria (Figura 15), e que a maioria dos estudantes (70,9\%), apontou para a compreensão de Educação Ambiental de acordo com agrupamento (A14). 


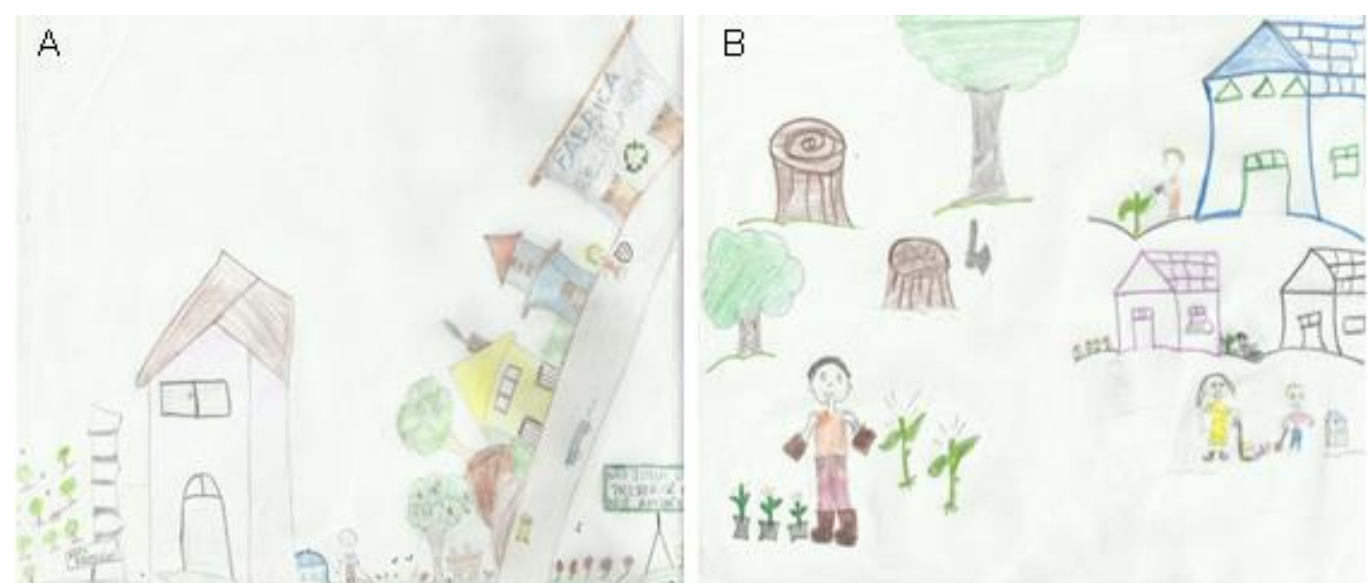

Figura 14: $A$ e B - Exemplos de agrupamentos das correntes de Educação Ambiental: A) conservacionista, resolutiva, humanista; B) conservacionista e humanista.

Fonte: A - K.A., 6ํㅡㅁ (2013); B - L.F., $7^{\circ}$ ano (2013).

Após a ressignificação observou-se que os alunos passaram a compreender Educação Ambiental como a soma de interações inerentes ao meio ambiente, a qual inclui as relações naturais com as relações sociais. Para Dias (2006) de acordo com os princípios básicos da Educação Ambiental, o meio ambiente deve ser considerado em sua totalidade, ou seja, em seus aspectos naturais e os criados pelo homem.

Neste trabalho utilizou-se a aplicação de uma trilha, a qual não teve a pretensão de promover a Educação Ambiental e sim, dentro desse contexto, auxiliar na ressignificação da maneira de conceber natureza, meio ambiente e Educação Ambiental. As trilhas apresentam grande valor para as práticas de Educação Ambiental, auxiliando na formação de cidadãos críticos, atuantes sobre a realidade ambiental (COPATTI et al., 2010).

\section{Conclusão}

$\mathrm{Na}$ primeira etapa, em cada mapa mental verificou-se apenas uma concepção para cada categoria e a maior parte dos alunos apresentou uma percepção naturalista para natureza, problema para meio ambiente, e conservacionista/recursista para Educação Ambiental. Após a intervenção na trilha percebeu-se que houve a ressignificação de concepções onde na categoria natureza foi notado o predomínio do agrupamento $A 1$, o qual apresentou a maior agregação de concepções.

Para a categoria meio ambiente foi observado o predomínio do agrupamento $\mathrm{A} 8$ e a maior diversidade de combinações, e consequentemente o aumento de agrupamentos. A categoria Educação Ambiental foi representada pelo agrupamento $A 14,0$ qual apareceu em destaque e apresentou a associação com maior número de correntes. Esse novo entendimento se aproxima da promoção do respeito às diferenças e revela a aquisição dos valores sociais e de novas atitudes. 


\section{Agradecimentos}

Aos gestores da Escola em Regime de Convênio Estadual de Ensino Fundamental e Médio Cristo Redentor pela autorização de acesso às turmas pesquisadas, à coordenação do Centro Bíblico de Abaetetuba-PA pela colaboração na implementação da trilha e ao Corpo de Bombeiros do Estado do Pará pelo acompanhamento no trajeto percorrido na floresta.

\section{Referências:}

AIRES, B.F.C.; BASTOS, R.P. Representações sobre meio ambiente de alunos da educação básica de Palmas (TO). Ciência \& Educação, v. 17, n. 2, p. 353364, 2011.

ALMEIDA, P.M.; ORTIZ, A.C.M. Concepções de meio ambiente e Educação Ambiental entre acadêmicos e coordenadores de Cursos de Graduação do Centro universitário Franciscano, Santa Maria, RS. Disciplinarum Scientia. Série: Ciências Humanas, Santa Maria, v. 7, n. 1, p. 1-17, 2006.

ARRUDA, C.F.B. O processo de ressignificação de crenças e de mudança na prática pedagógica de um professor de inglês em educação continuada. 2008. 141 f. Dissertação (Mestrado em Linguística Aplicada) - Faculdade de Letras, Universidade Federal de Minas Gerais, Belo Horizonte, 2008.

BRÜGGER, P. Educação ou adestramento ambiental? 2.ed. Florianópolis: Letras Contemporâneas, 1999.

BUZAN, T. Use sua mente: como desenvolver o poder de seu cérebro. São Paulo: Integrare Editora, 2011.

CARVALHO, I.C.M. Educação Ambiental: a formação do sujeito ecológico. 2 ed. São Paulo: Cortez, 2006.

CARVALHO, V.S. Educação Ambiental e desenvolvimento comunitário. Rio de Janeiro: WAK, 2002.

COPATTI, C.E.; MACHADO, J.V.V.; ROSS, B. O uso de trilhas ecológicas para alunos do ensino médio em Cruz Alta - RS como instrumento de apoio a prática teórica. Educação Ambiental em Ação. n. 34, 2010. Disponível em: $<$ http://www.revistaea.org/artigo.php?idartigo=952\&class=21> Acesso em: 14 de outubro de 2012.

DIAS, G F. Atividades interdisciplinares de Educação Ambiental: práticas inovadoras de Educação Ambiental. 2. ed. São Paulo: Gaia, 2006.

DULLEY, R.D. Noção de natureza, ambiente, meio ambiente, recursos ambientais e recursos naturais. Agricultura em São Paulo, São Paulo, v. 51, n. 2, p. 15-26, 2004.

FERRARI, A.H.; ZANCUL, M.C.S. A Educação Ambiental nos projetos políticopedagógicos das escolas municipais de ensino fundamental da cidade de Araraquara/SP. Revista Eletrônica do Mestrado de Educação Ambiental. Rio Grande, v. 25, jul./dez. 2010.

revista brasileira educação ambiental 
JACOBI, P. Educação Ambiental, cidadania e sustentabilidade. Cadernos de Pesquisa, n. 118, p. 189-205, 2003.

LIMA, A.M.; OLIVEIRA, H.T.A (re) construção dos conceitos de Natureza, meio ambiente e Educação Ambiental por professores de duas Escolas públicas. Ciência \& Educação, v. 17, n. 2, p. 321-337, 2011.

LOUREIRO, C.F.B. Trajetória e Fundamentos da Educação Ambiental. 2 ed. São Paulo: Cortez, 2006.

MORAES, F.A. As concepções de meio ambiente e natureza: implicações nas práticas de Educação Ambiental de professores da rede estadual de ensino no município de Aparecida de Goiânia (GO). 2009. 104f. Dissertação (Mestrado em Educação em Ciências e Matemática) - Universidade Federal de Goiás, Goiânia, 2009.

PÁDUA, S.; TABANEZ, M. (Orgs.). Educação Ambiental: caminhos trilhados no Brasil. São Paulo: Ipê, 1998.

REIGOTA, M. A Educação Ambiental frente aos desafios apresentados pelos discursos contemporâneos sobre a natureza. Educação e Pesquisa, São Paulo, v.36, n.2, p. 539-553, 2010.

SANTOS, C.P. A Educação Ambiental: um estudo de caso no município de Vitória da Conquista - BA. 2007. 115 f. Dissertação (Mestrado em Desenvolvimento Regional e Meio Ambiente) - Universidade Estadual de Santa Cruz, Ilhéus, 2007.

SAUVÉ, L. Uma cartografia das correntes em Educação Ambiental. In: SATO, M.; CARVALHO, I.C.M. (Orgs.). Educação Ambiental. Porto Alegre: Artmed, 2005. cap. 1, p. 17-45.

SILVA, M.D.; CARNIATTO, I.; POLINARSKI, C.A. Projeto político-pedagógico como instrumento para Educação Ambiental formal. Anais do VII Enpec Encontro Nacional de Pesquisas em Educação em Ciências. Florianópolis, nov. 2009.

SILVA, S.N. Concepções e representações sociais de meio ambiente: uma revisão crítica da literatura. Anais do VII Enpec - Encontro Nacional de Pesquisa em Educação em Ciências. Florianópolis, nov. 2009.

TAMAIO, I. O professor na construção do conceito de natureza: uma experiência de Educação Ambiental. São Paulo: Annablumme: WWF, 2002. 